\title{
Research on Effective Teaching Methods for English-medium Instruction Computer Networking Course
}

\author{
Gu Haiyun*, Bo Hua \\ College of Information Engineering, Shanghai Maritime University, Shanghai, China \\ Email address: \\ hygu@shmtu.edu.cn (Gu Haiyun), huabo@shmtu.edu.cn (Bo Hua) \\ ${ }^{*}$ Corresponding author
}

To cite this article:

Gu Haiyun, Bo Hua. Research on Effective Teaching Methods for English-medium Instruction Computer Networking Course. Education Journal. Vol. 8, No. 6, 2019, pp. 279-285. doi: 10.11648/j.edu.20190806.17

Received: October 5, 2019; Accepted: October 31, 2019; Published: November 8, 2019

\begin{abstract}
Chinese universities have been strongly supported by government to promote English-Medium Instruction (EMI) in the past two decades. While EMI is not simply translating lecture contents into English, the teaching methods should be adjusted accordingly. This study aims at seeking effective EMI teaching methods for engineering courses, taking the case of Computer Networking course in Shanghai Maritime University. Several computer-aided teaching methods have been practised, including interactive teaching with Rain Classroom, class demonstration with Wireshark and Packet Tracer, video review, online teaching resources, and hands-on projects. Based on our teaching experience, a 3-step interactive teaching routine was set up and practiced. The comparing result of three consecutive years' final exam scores and labs scores show an overall improvement of the students' learning outcomes. An online questionnaire was designed to investigate the students' opinions on teaching contents and methods. The collected survey results and feedbacks show that most of the students approve of our EMI teaching methods. But there are up to $27.5 \%$ students who still consider EMI academic course is difficult. The cross comparative result of the online students' survey reveals that the students' previous EMI experience greatly affects their perceived level of difficulty. It should be very helpful to offer an introductory EMI course or an ESP (English for Special Purpose) course for the engineering freshmen to prepare them for the follow-up EMI academic courses.
\end{abstract}

Keywords: English-medium Instruction, Interactive Teaching Methods, Computer Networking

\section{Introduction}

Since the late 1990s, Chinese universities have been growing rapidly in order to cultivate more high-level personnel. Chinese government has introduced a series of policies to balance between the expansion of enrolment and the quality of education [1]. EMI has been continuously promoted as an approach to internationalize the high education and enhance the universities' academic ranking in China.

With the discipline of science and engineering education, EMI is definitely not simply translating the contents into English, the teaching methods should be adjusted accordingly. The methodology suited to EMI involves shifting the focus of classes from the transfer of information to greater student participation and supporting the construction of understanding by students with the help of resources and scaffolding by the teacher [2]. An educational methodology may result superior consequences in teaching a specific course, whereas it fails in that of the other course [3]. So it is important for the EMI teachers to find suitable teaching methods for their own courses and students.

Teaching Computer Networking is quite a challenging task, considering of the fast development and variable technologies of Internet. The general goal of teaching methods is to encourage students to be active, i.e., to make them ask questions or to let them develop solutions to certain computer networking problems [4]. [5] used in-class quizzes, hands-on problem solving and application development practices, instead of the traditional homework and group project studies, to get better individual educational assessment. [6] presented a problem-based teaching approach in Computer Network. [7] discussed the flipped classroom and gamification teaching methods by using Cisco networking academy.

According to our experience in teaching Computer 
Networking, the problem with flipped classroom is that some of the students often forget to watch the video lessons, and come to class unprepared. This makes the in-class discussion inefficient, especially in large classes. Chinese traditional teaching methods are usually teacher-centered, focusing on theories and principles. It is partly because of the pressure to cover many contents within limited teaching hours, partly because of the passiveness of Chinese engineering students [8]. In order to motivate the undergraduates' learning desires and improve their learning outcomes in Computer Networking course, this paper presents a blended teaching method which includes adopting an interactive teaching tool (Rain Classroom), designing class demonstrations with Wireshark and Packet Tracer, and providing on-line teaching resources and hands-on projects. The comparing result of three consecutive years' final exam scores and labs scores show an overall improvement, and the students' survey results have been analyzed for more understanding.

\section{Teaching Methods}

Through this course, the students are supposed to learn the principles of TCP/IP protocol stack in the current Internet. The basic teaching method is a top-down approach [9], beginning at the application layer, the most familiar part of the students, and working the way down towards the physical layer.

\subsection{Interactive Teaching Tool - Rain Classroom}

Rain Classroom is a wisdom teaching tool launched by Tsinghua University in April 2016 [10]. Based on cloud computing, mobile internet, and data mining technologies, Rain Classroom was designed to provide intellectualized teaching support to higher education. It is integrated with PowerPoint and WeChat, the most popular social app in China. Rain Classroom provides multiple ways of interactions:

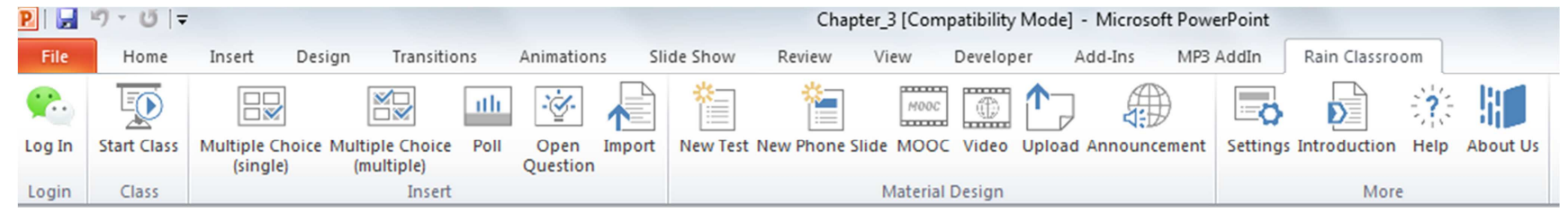

Figure 1. The integrated toolbar of Rain Classroom in PowerPoint.

i. Slides synchronization: to push the PowerPoint slides from the teacher's computer in the classroom to the students' smartphones synchronously during the lectures.

ii. Instant questions: to check the learning outcome by pushing prepared questions inserted into the slides to the students' smartphones, collecting the answers, and displaying instant statistics.

iii. Live commentary: to provide open discussion function by allowing the students to upload live comments that would be shown on the screen instantaneously through the overhead projector in the classroom. iv. Courseware release: to upload the slides, lecture notes, lecture videos, previous test papers, etc., to the course database on Rain Classroom for students to prepare and review.

v. Notice release: to inform the students of course-related information via the teaching log on Rain Classroom.

vi. Lecture summary: to automatically collect and analyze teaching data after each lecture. Help teachers to easily get known with the whole or individual learning situation.

Based on our experience in using Rain Classroom, a 3-step interactive teaching routine was set up, as shown in Figure 2:
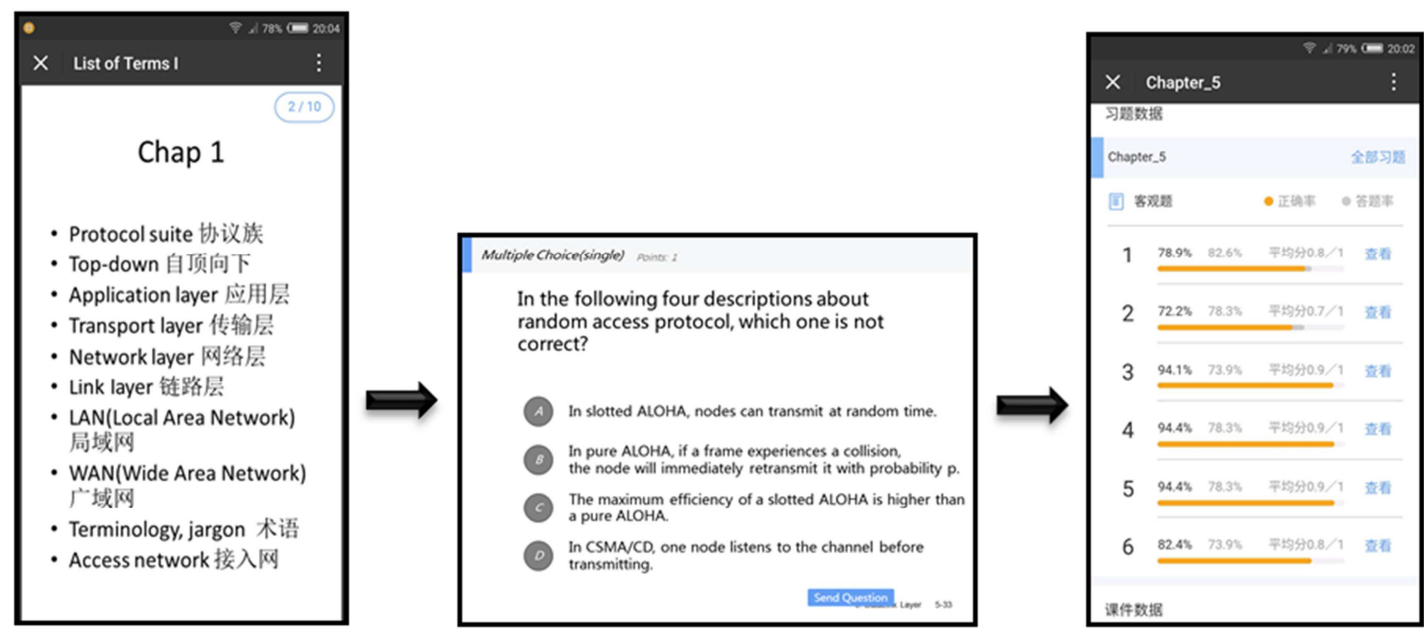

Figure 2. Illustration of the 3-step interactive teaching routine. 
Step 1, before each lecture, the teachers release a list of academic terms and expressions in advance to help the students prepare for the next lecture. According to our previous survey on engineering students' attitude to EMI [11], it is not only the lack of English proficiency but also the lack of academic terms that influence the students' understanding of course contents.

Step 2, during each lecture, the teachers push instant questions to students' smart phones every 20-30 minutes to regain the students' full attentions. The questions should be carefully designed. To help students understand and remember the teaching contents, it is better to choose basic concept questions [12]. Hard questions cannot help to encourage students in an EMI class.

Step 3, after each lecture, Rain Classroom provides the preliminary statistical result of teaching data collected during the lecture to help the teacher get known of students' learning situation. The teachers can adjust the lectures' contents or schedule accordingly.
This 3-step interactive teaching routine based on Rain Classroom has effectively enhanced the interaction between the teachers and students, the students' participation in classroom, and the teaching effects.

\subsection{Class Demonstration}

The best way to understand network protocols in Internet is to demonstrate it. For convenience, light weight software is more suitable for class demonstration.

During this course, Wireshark, a free and open source packet sniffer, was used to help students directly observe how the protocols work in the real network environment. For example, to teach the Web's application-layer protocol, HTTP, teachers can use Wireshark to capture packets sent and received by the web browser. By analyzing the structure of captured packets, the students would get a more vivid perception and a better understanding of the HTTP details and the network setting.

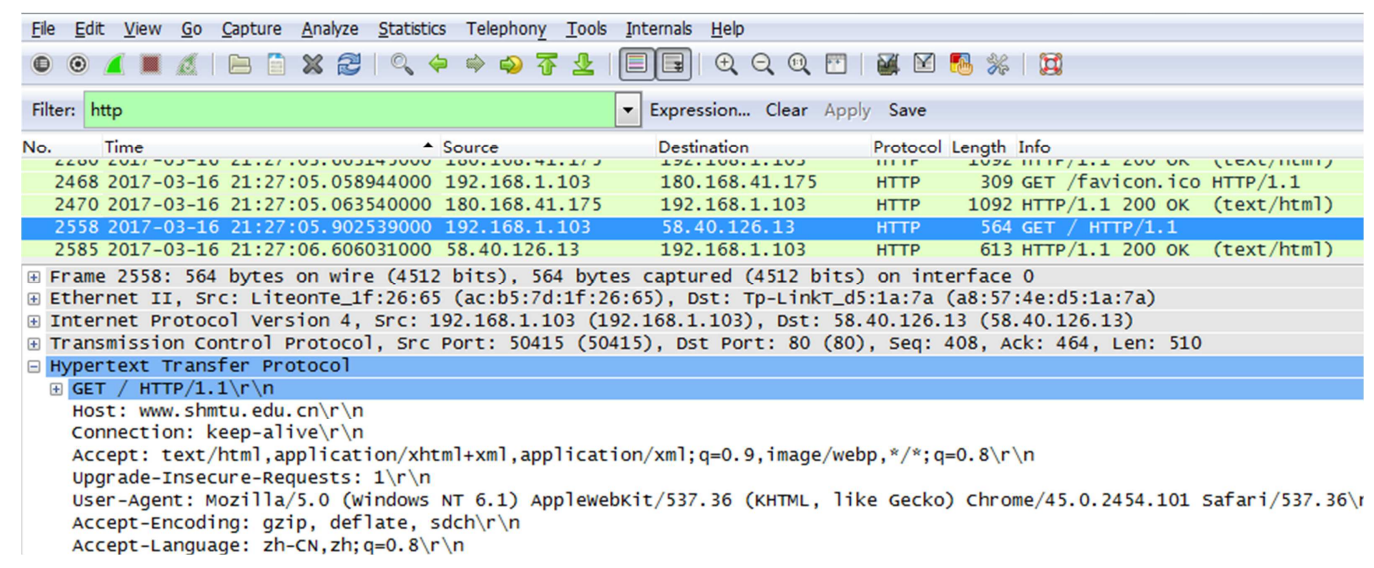

Figure 3. Using Wireshark to explain the HTTP request.

Packet Tracer, a network simulation tool from Cisco, is very suitable for beginners. It was also adopted in our lectures to show the students how to set a specific network topology, and analyze the operating principles. For example, a simple lab was designed to illustrate the DHCP (Dynamic Host Configuration Protocol), which is popular used in wired and wireless LAN. Packet Tracer provides step by step simulation and graphical results analysis.

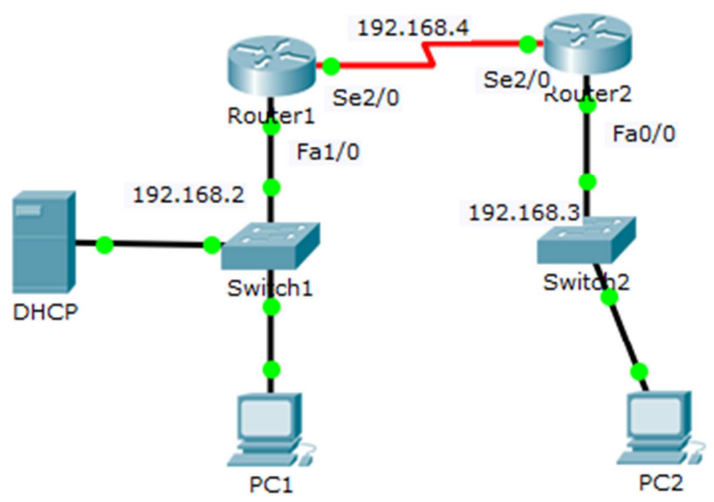

Figure 4. The topology of DHCP lab in Packet Tracer.
Furthermore, Teachers can prepare different situations in advance to cultivate the students' ability of analyzing and solving problems.

\subsection{Video Review}

Videos can be used by students to review and reflect their engineering knowledge [13]. Today, there are massive online learning video resources that could be used as supplements to classroom learning. But on the other hand, it is a little difficult for a sophomore to search for the most suitable learning videos.

In this semester, in order to strengthen the students' understanding of academic terms, we took 5-10 minutes every 2 or 3 lectures to let the students watch a well-chosen short video which should be related to the lecture's topic with an appropriate level of difficulty. It was supposed to help the students to review the academic terms and concepts they've learned.

According to the students' feedback, this "video review" method is very welcomed for giving the students a sense of achievement. It could be very helpful to improve the students' communication skills that they would need in their future 
careers.

\subsection{Online Course Resources}

The online course platform of our university provides various learning resources of this course for the students, including the lecture videos with bilingual captions, the slides, the questions solutions, the guidance of hands-on projects, the list of references, etc. As a beneficial supplement to classroom teaching, the course website also provides a discussion area to improve the extracurricular communication.

Since our students are from different parts of China, their English proficiency is quite different. For some students, the online course platform is also acting as an effective way to help them keep pace with the schedule.

\subsection{Hands-on Projects}

The corresponding experimental course is usually arranged in the second half of the semester, after the learning of network principles. Along with the lecturing, we also assigned hands-on projects to let the students get a feel of the real network environments. The interactional skills are important to engineers for working in teams and communicating with clients [14], so our students are suggested to work in group with 2-3 classmates.

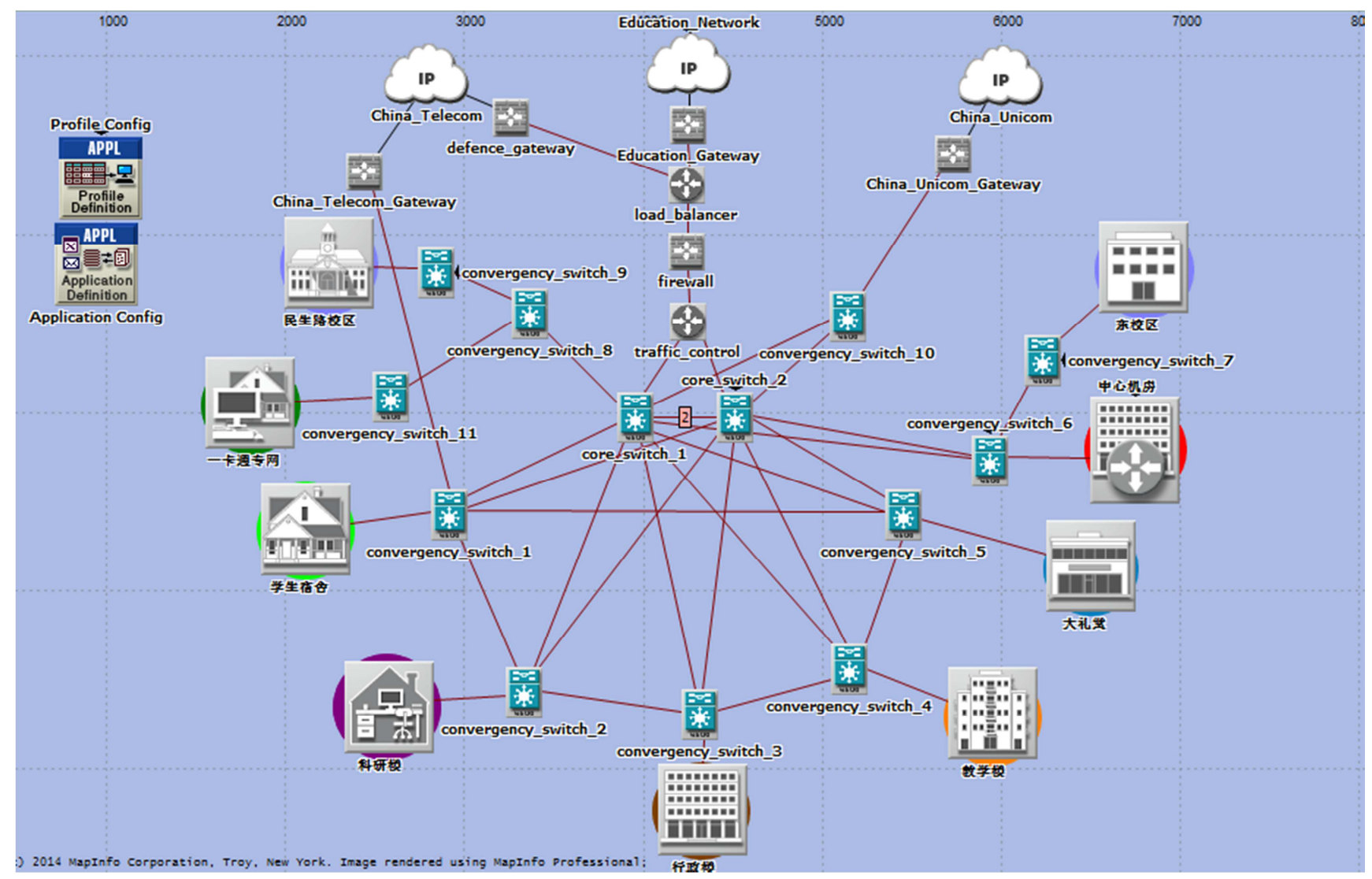

Figure 5. Campus network topology in the students' project reports.

For example, a campus network simulation project was designed for the students to get known of the topology of our campus LAN and learn how to use Opnet to simulate a network. This project would become more and more complex with the deepening of the students' understanding of network protocols.

\section{Evaluations}

At the end of this course, we analyzed the scores of the final exam and labs, and designed an online questionnaire to investigate the students' opinions on Rain Classroom and this EMI course. Students were also invited to give their suggestions through the discussion area in Rain Classroom.

\subsection{Final Exam Scores}

Table 1 shows the 3-year comparison of the distributions of the students' final exam scores by counting the percent of the students in each grade.

i. In 2016, with bilingual teaching method, 69 students' scores were concentrated between 40 points to 80 points;

ii. In 2017, with applying EMI teaching method, 72 students' scores were well differentiated, and the failure rate had been cut by half;

iii. In 2018, with Rain classroom was adopted in this EMI class of 69 students, the percent of both Grade A and B show an improvement. 
Table 1. The Distributions of Students' Test Scores.

\begin{tabular}{llll}
\hline \multirow{2}{*}{ Test Grade } & \multicolumn{3}{l}{ Percent of Students } \\
\cline { 2 - 4 } & $\mathbf{2 0 1 6}$ & $\mathbf{2 0 1 7}$ & $\mathbf{2 0 1 8}$ \\
\hline A (100-90) & $0 \%$ & $1.39 \%$ & $7.25 \%$ \\
B (89-80) & $0 \%$ & $13.89 \%$ & $18.84 \%$ \\
C (79-70) & $10.14 \%$ & $27.78 \%$ & $17.40 \%$ \\
D (69-60) & $46.38 \%$ & $33.32 \%$ & $31.88 \%$ \\
E (59-) & $43.48 \%$ & $23.62 \%$ & $24.63 \%$ \\
\hline
\end{tabular}

It should be mentioned that in 2016, the course was taught bilingually, but the final exam was in English, it might lead to unsatisfactory grades of some students.

Comparing to 2017, the percent of students who failed this course in 2018 is not reduced but even slightly increased. It seems that the interactive teaching methods have no much help for the students who are not yet adapted to EMI.

But generally speaking, EMI with the interactive teaching methods effectively improved the students' learning outcomes.

\subsection{Labs Scores}

Table 2 shows the distributions of students' labs scores. The students' performances have also been improved. In particular, comparing to 2016, the percent of students in Grade A has doubled in 2018.

With EMI lecturers, class demonstration and hands-on projects, the students were obviously more familiar with the English academic software and devices. It would be very helpful for their future study and work.

Table 2. The Distributions of Students' Labs Scores.

\begin{tabular}{llll}
\hline \multirow{2}{*}{ Labs Grade } & \multicolumn{3}{l}{ Percent of Students } \\
\cline { 2 - 4 } & $\mathbf{2 0 1 6}$ & $\mathbf{2 0 1 7}$ & $\mathbf{2 0 1 8}$ \\
\hline A (100-90) & $18.25 \%$ & $25 \%$ & $36.4 \%$ \\
B (89-80) & $22.22 \%$ & $33.34 \%$ & $25.8 \%$ \\
C (79-70) & $58.32 \%$ & $41.66 \%$ & $34.8 \%$ \\
D (69-60) & $1.21 \%$ & $0 \%$ & $3 \%$ \\
E (59-) & $0 \%$ & $0 \%$ & $0 \%$ \\
\hline
\end{tabular}

\subsection{Online Questionnaire and the Survey Results}

The online questionnaire includes 5 choice questions:

Table 3. Question 1. Have you ever had experience on EMI?

\begin{tabular}{ll}
\hline Choices & Percentage \\
\hline A. Yes, it is a bad experience. & $5 \%$ \\
B. Yes, it is a good experience. & $20 \%$ \\
C. No experience. & $75 \%$ \\
\hline
\end{tabular}

This results shows that it is a good start for our course to have most of the students without resistance to EMI. But on the other hand, $75 \%$ of our students are lack of experience of learning academic course in English. This situation should be more or less similar in other Chinese universities. It hints that more efforts are needed in promoting EMI in engineering education in China.
Table 4. Question 2. How difficult is this EMI course to you?

\begin{tabular}{ll}
\hline Choices & Percentage \\
\hline A. Very simple. & $0 \%$ \\
B. Simple. & $22.5 \%$ \\
C. Average. & $50 \%$ \\
D. Difficult & $27.5 \%$ \\
\hline
\end{tabular}

For an introductory course of computer networks, this survey result of the curriculum difficulty is not as good as expected. Obviously, EMI academic course is still not easy for most of our students. Considering that this is the first EMI academic course for most of our students, it can be inferred that EMI do increase the burden of learning at the beginning.

Table 5. Question 3. What do you think has improved through this course?

\begin{tabular}{ll}
\hline Choices & Percentage \\
\hline A. Academic terms. & $85 \%$ \\
B. Professional skills. & $60 \%$ \\
C. English reading abilities. & $47.5 \%$ \\
D. English communication skills. & $15 \%$ \\
\hline
\end{tabular}

Question 3 is a multiple choices question. It was designed to investigate the students' interests on the course contents. This course is supposed to teach the students the basic concepts and principles of computer networks. From this result, it seems that the goal is basically accomplished. Because there is not many chances for teachers to do one-to-one communication with students, so it seems that our EMI course didn't help much with the students' English communication skills.

The study [15] reported that academic listening practices in English language are challenging for international students in Malaysia. With more and more international students studying in the engineering degree programs in China, more attention should be paid to improve the communication skills in EMI classroom.

Table 6. Question 4. Which function of Rain Classroom is your favorite?

\begin{tabular}{ll}
\hline Choices & Percentage \\
\hline Slides synchronization. & $87.5 \%$ \\
Instant questions. & $52.5 \%$ \\
Notice Release. & $60 \%$ \\
Courseware Release. & $15 \%$ \\
\hline
\end{tabular}

Question 4 is also a multiple choices question. It is not surprising that the slides synchronization is the most popular function, because the students could vary the studying pace slightly and benefit from this personalized learning environment. Based on our teaching experiences, the function of slides synchronization in Rain Classroom is especially suitable for large classrooms. Instant questions help the teachers a lot to get known with the students' learning situations. Notice Release is very convenient because it would be reminded on the mobile APP. The courseware release function looks a bit superfluous for there are already other ways to get the courseware.

Question 5. Which part of the lecture contents do you like best?

A. Learning Resources; 
B. Class demonstration;

C. Video Review;

D. Hands-on Projects.

This is a sequencing question. The survey result is $B-C-D-A$. So the students like the class demonstration experiments best. But unfortunately, with the limited teaching hour, there is no time for the teacher to do demonstration every time, and not all contents are suitable for a class demonstration. The video review got the second highest vote, showing that the time spent is worthwhile. Hands-on Projects got the third place, according to some students' feedbacks, they think that some projects need too much time outside class. It is a little surprised that learning resources got the least votes. One possible reason is that nowadays, there are so many other access to learning resources on Internet.

\subsection{Cross Comparative Result}

Even though English proficiency plays a crucial role in students' academic achievements in EMI classes, students with high language proficiency can also experience the same difficulties. This is because academic English is a different genre from daily-used English [16].

Figure 6 shows a cross comparative result of Question 1 and Question 2. Question 1 is about the previous EMI experience. Question 2 is about the students' perceived level of difficulty of this course.

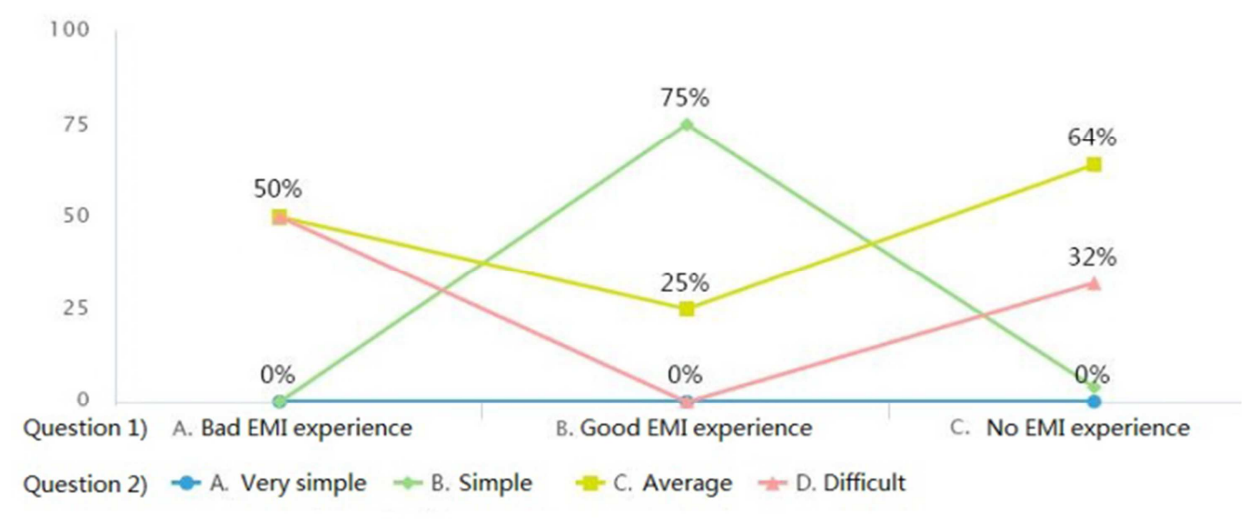

Figure 6. Cross comparative result of Question 1 and 2.

The students who had a good EMI experience are more easily to adapt to this course, while the students with a bad EMI experience or no EMI experience are more likely to feel that this course is difficult.

This cross comparative result gave us some enlightenment. In the information technology college of our university, currently there are few EMI courses for freshmen. This is the main reason why $75 \%$ students in this Computer Networking course had no EMI experience before. The other $25 \%$ students had got a good or bad EMI experiences from some public elective courses which are often not in engineering. So, in fact, all our students are in the same level of academic English before this course. It seems that a good EMI experience can greatly reduce the students' anxiousness in EMI classroom. It might be very helpful to offer a simple introductory EMI course of information technology for the freshmen to prepare them for the follow-up professional courses. Another solution is to provide an ESP (English for Special Purpose) course before any EMI academic course to cover the basic professional knowledge and terms.

\subsection{Students' Feedbacks}

The students also gave us detailed suggestions to this course through our online survey. Most of them agree that EMI should be promoted in engineering education, especially in the information technology disciplines. But nearly a half of the students hope that teachers could use Mandarin to explain the academics terms and concepts on the first appearance. Speaking about the teaching methods used in this semester, some typical suggestions are as follows:

i. "It is good to use human analogies to explain the network protocols. The class demonstration is also cool. But the simulation project of the campus network is not easy..."

ii. "I like the interactive questions in Rain Classroom, but not very into the live comment function."

iii. "Please add Chinese annotations for the academic terms on the slides, at least in the first Chapter."

iv. "I hope the lecture could be a little slower."

v. "The instruction of Labs could be more specific."

For EMI academic course, if the teacher uses the same teaching speed as for Chinese-medium instruction course, it is undoubtedly discourage the students. Even with the previously discussed teaching methods, the teacher should give the students a certain time to adapt to the teacher's English accent, professional English vocabulary and expressions. For example, for the first one or two lectures, the teacher could slow down the speech speed, use fixed expressions, and repeat the use of professional terms to enhance the students' understanding. For theoretical contents, in addition to lowering the lecture speed, a summary list or a finite state machine could be very helpful.

As the computer networking terms are originally in English, it is natural and convenient to use English academic 
textbooks and materials for the class teaching. The advantage is that learning terms and concepts directly in English avoids the ambiguity problems caused by translation. The disadvantage is that the examples and instances in the referenced books are usually popular in America, not in China. For computer networking course, the most advantageous teaching method is to use real life examples. So our teaching contents are combined with the actual situation of China's Internet and our campus network to be more acceptable.

\section{Conclusion}

This paper aims at seeking effective EMI teaching methods for Computer Networking course. By using Rain Classroom teaching tool, a 3-step interactive teaching routine is applied to enhance the students' participation and the teacher's understanding of students' learning situation. Besides, a series of teaching approaches are used to increase the teaching effects, including class demonstration, video review, online learning resources, and hands-on projects. The final exam scores proved the effectiveness of our EMI and interactive teaching. The online survey results and the students' feedbacks show that the students mostly approved of our interactive teaching methods. The cross analysis result indicates that the students' lack of EMI experience could be an important factor of EMI course learning outcomes. Our suggestion is to arrange an introductory EMI course or an ESP course for the engineering freshmen to prepare the students with the learning abilities under English environment. EMI teachers could also consider to cooperate with ESP teachers.

As the Oxford EMI report suggested, each country and each context where EMI is used is unique [17]. In promoting EMI in engineering education, Chinese Ministry of Education needs to develop more detailed guidance and more training opportunities for EMI teachers in engineering. As long as we know, there is no formal qualifications required of university teachers to teach in English. For different disciplines, the standard might not be the same. Further research is clearly needed.

\section{Acknowledgements}

This paper is supported by the Project of Shanghai Model EMI Course for international students, and the Online Course Project of Shanghai Maritime University.

\section{References}

[1] K. Ngok, "Massification, bureaucratization and questing for "world-class" status higher education in China since the mid-1990s," Int. J. Educ. Manage., vol. 22, pp. 547-564, 2008.

[2] O'Dowd R. (2015, April 12). The Training and Accreditation of Teachers for English Medium Instruction: A Survey of European Universities [Online]. Available: https://formacion.uam.es/pluginfile.php/110823/mod_resource
/content/1/EMI\%20Survey_Report_ODowd.pdf.

[3] T. R. Murray and V. N. Kobayashi, Educational Technology Its Creation, Development and Cross-Cultural Transfer, Elsevier, 2014.

[4] Schönwälder Jürgen, Timur Friedman, and Aiko Pras, "Using Networks to Teach About Networks (Report on Dagstuhl Seminar \#17112)," Acm Sigcomm Computer Communication Review, 2017, 47 (3), pp. 40-44.

[5] Atila Bostan, "Teaching Computer Networks: Theory and Problem Solving," in Journal of Advances in Computer Networks, 2015, vol. 3, No. 4, pp. 299-302.

[6] Lin TANG, "Study on Teaching Methods of Computer Network Course Based on Analogy and Problem-based Approach," in $20172^{\text {nd }}$ International Conference on Education and Development, pp. 222-227.

[7] Zhamanov, Azamat, and Zhulduz Sakhiyeva, "Implementing flipped classroom and gamification teaching methods into computer networks subject, by using cisco networking academy," in 2015 Twelve International Conference on Electronics Computer and Computation (ICECCO), pp. 1-4.

[8] Gu H. and Ren L., "English-medium instruction in engineering education: Practices, challenges, and suggestions," in IEEE International Conference on Teaching Assessment, and Learning for Engineering., Hongkong, China, 2017, pp. 229 232.

[9] Kurose J. F. and Ross K. W., Computer Networking: A Top-Down Approach Featuring the Internet Package. Addison-Wesley, 2002.

[10] Wang S. G., "Rain Classroom: The Wisdom Teaching Tool in the Context of Mobile Internet and Big Data," Modern Educational Technology, 2017, vol. 5, pp. 26-32.

[11] Gu H. and Ren L., "A survey of Chinese Engineering Students' Attitudes toward EMI", in 3rd International Conference on Management, Education Technology and Sports Science, Guilin, China, 2016, pp. 158-161.

[12] I. Rothe, "How to handle large classrooms of engineering students: Sharing experiences with applying three methods/practices including evaluation results and personal feedback," in IEEE Global Engineering Education Conference, Abu Dhabi, UAE, 2016, pp. 11-14.

[13] Ting Y. and Tai Y., "Work-in-progress: Students' self-making videos for the tandem learning of two engineering courses," in IEEE International Conference on Interactive Collaborative Learning, Florence, Italy, 2015, pp. 1-4.

[14] Tsou W., "Interactional Skills in Engineering Education," in English as a Medium of Instruction in Higher Education, Springer, Singapore, 2017, pp. 79-93.

[15] Kaur M. "Academic Listening Practices among International Graduate Students in English as Medium of Instruction Context Difficulties and Corrective Measures," Pertanika Journal of Social Science and Humanities, 2016, vol. 24, pp. 1579-1599.

[16] Chou, Ichia . "Helping Students Learn in EMI Courses Using Reciprocal Teaching: A Case Study of a Taiwan University," Asian Education Studies, 2016, vol. 1, No. 2, pp. 37-43.

[17] J Dearden, "English as a medium of instruction - a growing global phenomenon," British Council, 2014. 